\title{
SOBRE MORTE E POSSIBILIDADE
}

\author{
Écio Elvis Pisetta ${ }^{1}$ \\ "A inquietude vem de ti. É nada aquilo que te \\ move: tu mesmo és a roda / Que por si mesma gira \\ e nenhum repouso encontra" 2
}

\begin{abstract}
Resumo: Neste artigo desejamos explorar algumas relações entre morte e possibilidade. Ao chamarmos a atenção para o tema da morte, convocamos também nosso pensamento a dar um pequeno recuo, a fim de examinar os diversos preconceitos que sempre nos afetam. Assim, de uma compreensão corriqueira da experiência da morte buscaremos uma existencial, uma compreensão que esteja de acordo com o ser-no-mundo que cada ser humano é. Pertence a esta compreensão existencial o desenvolvimento dos caracteres de possibilidade e de privilégio da morte, diretamente ligados ao conceito existencial de ser-para-a-morte. Ocupa, para nós, um lugar norteador a obra Ser e tempo de M. Heidegger. Nosso propósito filosófico consistirá, então, num modesto exercício de elaboração de uma compreensão do fenômeno da morte.
\end{abstract}

Palavras-chave: morte; possibilidade; totalidade; existência; Heidegger.

\begin{abstract}
In this paper we will develop some relationships between death and possibility. When we put attention on death's subject, we call our thinking to go a little backwards, to look more accurately some prejudices that always influence us. So from a quotidian death's comprehension we will search an existential, a comprehension according to the being-in-the-world that every human being is. It belongs to this existential comprehension the development of the notion of possibility and death's privilege, directly attained to the existential concept of being-to-death. Heidegger's Being and time guide us in this work. Our philosophical purpose consists itself in a modest elaboration exercise of the comprehension of death's phenomenon.
\end{abstract}

Key-words: death; possibility; totality; existence; Heidegger.

${ }^{1}$ Doutor em filosofia pelo PPGF-IFCS-UFRJ e professor.

2 SILESIUS, Â. O peregrino querubínico. São Paulo: Paulus, 1996, p. 31, n. 37. 
No decorrer deste artigo traremos à tona algumas relações entre morte e possibilidade, não fazendo outra coisa a não ser pensar nossa existência no mundo. $\mathrm{O}$ interesse que conduz uma empreitada desta espécie pretende ser chamado de filosófico, não porque fornece algum tipo de doutrina ou coloca-se como defensor e intérprete de alguma filosofia já afamada, mas porque simplesmente pretende chamar nossa atenção acerca do que já sempre sabemos sobre tudo isso. Desta forma, nosso pensamento é convidado a dar um pequeno recuo. Mas este convite necessita de uma provocação constante. Assim, para que nossa atenção seja produtivamente encaminhada, buscando um afastamento compreensivo que desperte ainda mais uma vigília para nossa singular situação existencial, faz-se necessário conquistarmos uma nova perspectiva, uma nova luz ou ponto de vista. É a partir de um novo princípio de avaliação que, em geral, reavaliamos todo saber. Nossa atividade filosófica consistirá no exercício de elaboração de uma nova compreensão do fenômeno da morte.

A experiência da morte desafia continuamente a nossa compreensão. Este desafio assume múltiplos sentidos. Podemos pensá-la como aquele fenômeno que sempre resiste às mais insistentes tentativas de controle. $\mathrm{Ou}$ como aquele fenômeno que, de tão terrível, absurdo, arbitrário, ilógico, somente pode encontrar um sentido numa experiência que ultrapasse os limites da existência humana, fincada no aqui e agora de um ciclo vital limitado. $\mathrm{Ou}$ também como o extremo sem sentido da vida, de nossa existência, trazendo como conseqüência a impossibilidade de qualquer abordagem. Podemos, inclusive, nos moldar a uma determinada experiência de morte, construindo todo um comportamento "simpático" com aquilo que, sem muita reflexão, acreditamos compor o seu ser. E muito mais. Tudo isso porque, afinal, a morte ainda não veio mas já sempre nos afetou antecipadamente de alguma forma, produzindo uma dolorosa consciência e gerando os mais diversos comportamentos pessoais ou coletivos. Ocupar-se com a morte seria ocuparmo-nos de um fenômeno que, em si mesmo, consiste na negação de toda possibilidade de compreensão, inclusive da morte mesma. Mas será que, a partir destas reflexões, assumimos suficientemente o fracasso de qualquer empreitada rumo a alguma forma de apropriação do fenômeno da morte? Ou será que todas estas impossibilidades ainda resguardam a possibilidade de uma compreensão própria de nossa existência no mundo? Então, como a experiência da morte pode ser-nos acessível? Como pensar o estranho "limi- 
te” característico desta experiência-limite? E, em sendo possível uma compreensão do fim que pertence ao ser humano, como esta compreensão pode, em certo sentido, influenciar tudo o que acontece "antes" da morte? Como se apresenta para si mesma uma existência sintonizada com seu fim, com sua extrema possibilidade, ou seja, sua impossibilidade? Se conseguirmos perceber uma certa coerência em perguntas desta espécie, então podemos afirmar que a experiência da morte possui sua peculiar textura ontológica.

No século XX uma obra em especial, Ser e tempo $o^{3}$, coloca a questão pelo sentido do ser em geral. Como o autor Martin Heidegger, logo de início, chama a atenção, é preciso novamente despertar o interesse para essa questão. Para tanto, torna-se necessário colocar novamente a questão pelo ente que, entre outras características, possui aquela de questionar. Trata-se do ser humano, cujo modo de ser é explorado-interpretado na analítica da presença, do Dasein. ${ }^{4}$ Desta forma, pertence essencialmente a todo trabalho ontológico, uma investigação acerca do modo de ser daquele ente que sempre já somos, o esforço de pensar de novo o modo de ser do humano. A analítica da presença, desenvolvida em Ser e tempo, coloca-se esta tarefa. Conduziremos nossas reflexões, se não em seu completo conteúdo, pelo menos em sua estrutura, a partir de algumas orientações fornecidas por este autor e pela obra citada.

No trabalho de elucidação do modo de ser do homem que se concretiza numa infinidade de realizações, vem à tona o jogo existencial entre ontologia e morte, entre a compreensão herdada e simplesmente dada de homem, de mundo, de vida e a proposta de uma nova compreensão a partir da experiência da morte. Como se mostra o ser humano, a existência, o mundo, enfim, o ser, a partir da experiência humana da morte? Com isso dizemos

\footnotetext{
3 HEIDEGGER, Martin. Ser e tempo. Trad. Revisada de Márcia de Sá Cavalcante Schuback. Petrópolis: Vozes; Bragança Paulista: Ed. Universitária São Francisco, 2006. Já que esta é nossa fonte principal, para simplificar, citaremos no rodapé apenas a abreviação "ST" para Ser e tempo, seguida do parágrafo e da página correspondentes.

${ }^{4}$ Manteremos a tradução brasileira de "presença" para Dasein, sobretudo nas citações. Preferimos, no entanto, grifar o termo. Por meio da "presença" procura-se sempre de novo colocar a questão pelo ser do homem e nela permanecer como tarefa intransferível. Por isso, este termo não deve ser interpretado meramente como sinônimo de homem ou de ser humano. Investiga-se, na analítica da presença, a dinâmica de constituição de homem e de ser humano. Assim, mesmo no uso que fizermos dos termos "homem" e "ser humano" permanecerá, para nós, ainda em discussão esta dinâmica de constituição.
} 
que a experiência da morte - tal como a interpretamos a partir de Ser e tempo - pode mover-nos rumo a uma compreensão mais autêntica do modo de ser do ente que nós sempre somos e também nos auxiliar, de modo simples e provisório, numa aproximação à questão do ser. $\mathrm{O}$ ente que nós mesmos somos deve ser o primeiro a ser interrogado em seu ser. E este se mostra também em sua mortalidade. Desta forma resumimos nossa claudicante empresa.

\section{Visualização do problema.}

Façamos uma pequena apresentação de Ser e tempo e da parte que nos interessa, a análise existencial da morte.

Grosso modo, na primeira seção de Ser e tempo, faz-se uma "análise preparatória dos fundamentos da presença” (§ 9 ao $§ 44)$. Diversos existenciais são apresentados e explorados, tais como presença (Dasein), existência, serno-mundo, manual e manualidade, mundo circundante, a espacialidade da presença, o impessoal, disposição ou tonalidade afetiva, compreensão, interpretação, discurso, decadência, estar-lançado, verdade, etc. Na segunda seção, “presença e temporalidade” (§ 45 a $\S 83$ ), Heidegger se ocupa com a conquista de uma compreensão do tempo como o horizonte a partir do qual a colocação da questão pelo sentido do ser possa ser novamente realizada. Outros existenciais são trabalhados nesta seção, tais como o ser-para-a-morte, a decisão, a decisão antecipadora, a temporalidade, a historicidade, etc. Interessanos, de modo especial, uma certa direção esclarecida logo no início desta segunda seção.

$\mathrm{Na}$ seção anterior (a primeira) predominava uma certa interpretação impessoal e imprópria da presença, portanto, parcial ou incompleta. Isto não conduziria a analítica a um fracasso, já que, desta forma, não se conseguiria dar conta de uma compreensão total do ser humano? Tornou-se necessário, então, a conquista de uma compreensão própria deste ente, pelo menos se se quiser apreendê-lo em sua totalidade e unidade. Neste contexto Heidegger confronta-se com a temática da morte, experiência extrema, cunhando a interpretação da morte que cabe ao ser humano, e o ser humano compreendido existencialmente a partir dela, como ser-para-a-morte (Sein-zum-Tode) (§46-§53). A introdução desta temática, neste lugar, pode ser justificada pelo fato da morte ser sempre e continuamente o extremo "ainda-não" da vida. Assim, se não se puder "juntar" a morte à vida, então se deverá renunciar a 
uma compreensão do ser humano em sua totalidade. Por um lado, a morte deixa-se iluminar pelo foco dos existenciais compreendidos de maneira imprópria e, por outro, ela mesma ilumina e exige um mostrar-se distinto dos mesmos existenciais.

O que se impõe, nesta investigação, é a conquista de uma nova compreensão da morte e, igualmente, da existência. É preciso ultrapassar uma compreensão simplesmente dada dos entes. Como? Interpretando-os a partir de sua possibilidade de ser, ou seja, ganhando, à força de reflexão, um entendimento dos entes em sua possibilidade "vindoura" e não em suas cristalizações já "coisificadas". Atingiríamos, assim, uma compreensão existencial que interpreta a "vida" como horizonte aberto de ser, onde, cada vez, o uno e o múltiplo, o singular e o total, encontram-se numa tensão constituinte, autogerativa. No ser-para-a-morte encontramos toda esta provocação ontológica. Façamos, então, algumas considerações sobre a necessidade de se interpretar a morte como ser-para-o-fim.

\section{0 fenômeno da morte.}

Do $\S 46$ até o $§ 50$ de Ser e tempo, entre outras coisas, salienta-se que uma compreensão existencial da morte torna-se impossível a partir de uma interpretação simplesmente dada dos fenômenos. Quando algo se torna evidente, dizemos, já "sabemos do que se trata". Por conseqüência, permanece uma obviedade tão calada em nós que não necessita de questionamento. Quando dominam as concepções simplesmente dadas vivemos uma espécie de letargia da existência, uma espécie de sonambulismo funcional. Em geral, é sob o predomínio deste modo de ser que conduzimos nossa vida. Sob o comando de uma vida ou de um modo de ser "impessoal" (Das Man ["a gente”], das Man-selbst, o impessoalmente-si-mesmo ${ }^{5}$, para caracterizar nosso jeito mais comum e próprio de ser) sentimos nossa existência como todo mundo a sente e, daí, também, como uma espécie de experiência desenraizada e desenraizante. Nossa possível singularidade "dilui-se" na universalidade do que é comum, do que está na ordem do dia. Se vivemos, em geral, impessoalmente, é justo perguntarmos se existe a possibilidade de uma vida "pessoal”, própria, singular, isto é, não simplesmente pautada por uma compreen-

${ }_{5}$ ST §27, p. 186. 
são meramente dada ou sonâmbula da existência. A experiência da morte pode nos conduzir, de modo privilegiado, a esta compreensão.

A morte não é algo que, pertencendo à nossa existência de forma contingente, simplesmente nos falta no momento presente. Se fosse assim poderia se dizer que, enquanto ela não vem, eu sou, eu existo, e quando ela por fim vier, já não serei mais. A morte, então, e de certa maneira (Epicuro) ${ }^{6}$, não me diz nem dirá respeito. Sempre seria uma morte alheia. Neste sentido, viveríamos uma vida separada e aquém de uma possível experiência da morte. Seria então impossível experimentar uma morte própria. No entanto, a morte nos afeta, nos preocupa.

Se não posso, segundo o raciocínio anterior, fazer a experiência de minha própria morte, talvez possa fazê-la por meio da morte do outro. Mas, buscar esta experiência na morte alheia seria, igualmente, um equívoco. $\mathrm{Na}$ morte do outro, quem morre é o outro ${ }^{7}$. Desta forma não podemos nem experimentar a morte do outro, nem a nossa, já que quem morre é o outro. Reconhecemos que a multiplicidade de experiências da morte que encontramos enquanto estamos vivos muito nos ensina sobre a nossa vida e sobre como o ser humano comportou-se e comporta-se em relação à morte. Porém, queremos uma compreensão da morte de espécie diferente.

Precisamos levar em conta que detemos um estranho saber de nossa morte. Esta experiência nos possui, muitas vezes, de tal forma, que nos sentimos sem o chão que sustenta nossos pés. $\mathrm{E}$ isto desperta em nós uma consciência “incomum”. Diante de seu fato terrível, inalienável, em geral deslocamos nossa compreensão para as ciências, a religião, os rituais mais diversos, transformando a morte numa passagem, numa sina ligada às contingências do mundo, num aprendizado, num fato normal que pertence a todos os seres vivos, etc. O sentido da morte é procurado num lugar "posterior" ou "anterior" à nossa existência no mundo ou seu estranho sentido é justificado pela inexistência de uma suficiente "racionalização" ou, ainda, pela ineficiência atual de nossa "pesquisa positivo-científica”. Assim, nesta insuportável ausência de sentido, nosso comportamento mais geral consiste num desvio e numa fuga de nossa morte ${ }^{8}$. Da mesma forma que, tantas vezes, procuramos nos

\footnotetext{
${ }^{6}$ Cf, DASTUR, F. A morte. Ensaio sobre a finitude. Coleção Enfoques. Rio de Janeiro: DIFEL, 2002, p. 14.

${ }^{7}$ Cf. ST §47, p. 311-315.

8 Cf. ST §51, p. 328-331.
} 
outros uma experiência de nossa própria morte - algum paralelo -, também a procuramos nas diversas espécies de saberes que, em seu caráter de simplesmente dados ou evidentes, possuem um quê de alheio. Procuramos em outros lugares aquilo que, apenas por alguma mediação, encontramos como possibilidade nossa. Uma compreensão própria ou pessoal da morte parece ser coisa impossível. Para que se preocupar com isso? Afinal, além de não podermos experimentá-la, ela impossibilita toda outra experiência! Segundo Heidegger, devemos considerar que este raciocínio obedece a um modo simplesmente dado de pensar os fenômenos. Como podemos explicitar, em linhas gerais, este modo simplesmente dado de pensar?

De certa forma, as coisas e seus significados estão já ali, não necessitando de nenhum esforço de apropriação. Todos nós já recebemos como sabidos o homem em sua humanidade e o mundo em sua realidade. É o império da evidência, do comum, do universal e corriqueiro. Há, por exemplo, o ser humano e o mundo de um lado, e, de outro, o pensamento ou a razão que medeia estas instâncias, etc. Não importa, essencialmente, que esquema metafísico já consagrado fundamenta a nossa ou a alheia compreensão, interpretação e explicitação da realidade. O que importa é que o esquema ou a "realidade" tal como é compreendida, permanece evidente por si mesma, pressuposta como óbvia. Assim, esta evidência torna-se uma espécie de base, de fundamento e que funciona, então, como condição necessária para o desenvolvimento de todo um mundo enciclopédico de saber a posteriori. Para que, por exemplo, nos aventuremos a investigar os tipos, funções, causas, repercussões sociais, etc., da morte, em múltiplos sentidos, é preciso que detenhamos previamente, a cada vez, com maior ou menor clareza, uma certa compreensão da morte, como uma lâmpada que possa iluminar e possibilitar a identificação dos diversos fenômenos a serem "recolhidos e classificados". Esta compreensão é a priori, prévia, e condiciona nossas racionalizações posteriores. No caso das ciências em geral, esta compreensão prévia corresponde à sua positividade, a princípio não percebida, mas cujo positum préjaz, necessariamente, como algo pressuposto, evidente. Investigar existencialmente o tema consiste num trabalho de escavação destas evidências, onde se persegue, se vai atrás dos vestígios destas positividades, de seu ser simplesmente evidente e mais geral. Para quê? Para atingir $o$ último fundamento? Não. Antes para sermos tocados pela questão do fundamento. Exploram-se, assim, suas possibilidades, seu alcance, seus limites, isto é, principalmente, seu fundo e sustento de modo inteiramente distinto das ciências positivas. Se 
nestas, a exploração é progressiva, a partir de uma base comum, naquela (na existencial), ela é regressiva, buscando algo como um fundo "sem fundo", o abismo extraordinário de tudo o que é, que existe. Pois, à medida que pesquisamos positivamente, aceitando algo como evidente, este fundo com seus pressupostos não é questionando em suas condições de possibilidade, isto é, em seus limites, extensão, profundidade. Um determinado saber acerca da morte, por exemplo, assumiria o papel evidente de tornar-se todo o saber acerca da morte. "E todo o problema reside nesta obviedade", nesta evidência.

À primeira vista não devemos estranhar, então, a nossa desconfiança diante da acusação de existir um saber simplesmente dado que obscurece nosso acesso imediato aos fenômenos. Suspeitamos porque nosso inteiro mundo está em perigo, porque o questionamento existencial direciona seu olhar para o fundo sempre pressuposto e impensado sobre o qual construímos "tranqüilamente" a nossa existência. Basta apenas imaginarmos como é, de certa forma, doloroso abandonarmos o solo ou a terra a que estávamos acostumados e onde nos sentíamos seguros. Se, segundo Heidegger, o modo simplesmente evidente de abordar a temática da morte não consegue dar conta da possibilidade de uma morte própria, isto traz um desafio particular para o nosso pensamento, acostumado a certos esquemas intelectuais. Assim, se este modo "evidente" esgota-se, isto é, se não consegue satisfazer nosso questionamento em relação à morte, isto não significa que se esgotaram todas as possibilidades de compreensão. Restariam as existenciais ${ }^{10}$.

\section{Para uma compreensão existencial da morte.}

As possibilidades existenciais levam em conta o caráter relacional ou remissivo que expressa o modo de ser da presença, seu ser-no-mundo (In-derWelt-sein). O ser humano não está no mundo como a água está dentro de um copo. Presença, mundo, e o modo de ser que sempre ata ou liga presença e mundo, perfazem um dinamismo ininterrupto de unificação e diferenciação. Isto é, podemos, a título de estudo, separar seus momentos. Mas não podemos compreender adequadamente cada momento se não levarmos em

9 HARADA, H. Coisas, velhas e novas. À margem da espiritualidade franciscana. Bragança Paulista: IFAN, Ed. Universitária São Francisco, 2006, p. 14.

10 ST §46, p.310-311. 
conta uma compreensão da totalidade fenomenal. De um ponto de vista ontológico-existencial, a tematização da morte deve permanecer dentro dos limites deste mundo, sem ocultar nem escancarar ${ }^{11}$, o que sempre nos coloca dificuldades. Como experimentar a morte, vivendo? Não seria mais justo jogá-la para um "além-mundo"? No entanto, ela pertence ao ser-no-mundo que cada um de nós, como presença, sempre é. Deve-se buscar o que esta experiência possa nos oferecer em seu ser. Mas, não se está afirmando, com isso, que podemos experimentar uma morte própria, quando toda experiência corriqueira nos conduz ao oposto?

Em geral, minha experiência cotidiana da morte expressa-se num conjunto de vivências impessoais onde não sou propriamente eu que morro, mas, de fato, vivo ou experimento a morte como todo mundo, inserido num contexto, numa cultura, numa sociedade, numa época, num conjunto de costumes que me tomam o ser, isto é, substituem qualquer tentativa minha de morrer a minha morte. Este impessoal é tão forte e sedutor que, na maior parte das vezes, não chegamos nem a conceber em nossa vida a possibilidade de uma morte própria. Ou o fazemos apenas muito raramente. E, consideremos também, que toda esta nossa experiência corriqueira já está dominada por uma compreensão simplesmente dada dos fenômenos, onde a morte é previamente colocada de um lado e a vida humana de outro. Quando nos sentimos incomodados com este esquema metafísico que separa morte e vida, buscamos saídas comparando a morte humana com a de outros seres vivos, ou com outras experiências de fim, de término, de encerramento, e de totalidade. Repetimos o mesmo erro que encontramos na consideração destes fenômenos como simplesmente dados. A morte humana, existencialmente concebida, não deve ser compreendida a partir de uma noção de acréscimo, de "soma", como algo que será, em algum momento, colado ao ser humano. Nem como um "estágio" que, em algum momento, sobrevirá. Não deve ser compreendida como uma etapa, como o término de um processo, onde o ser humano encontrará sua completude deixando de ser, no fim! Como se obteria memória ou lembrança deste fenômeno?

Mas, nestas reflexões, não se está pressupondo descuidadamente uma vida contínua que fiscaliza, analisa, determina, permanecendo confortavelmente fora do fenômeno? A interpretação simplesmente dada sempre se encontra fora, num lugar seguro, e aquém do que pretende descrever. No

${ }^{11} \mathrm{Cf} . \mathrm{ST} \S 49$, p. 321-324. 
entanto, existencialmente, o ser humano é para a sua morte enquanto ele é, vive. Isto atinge cada ser humano de forma impartilhável. Daí, também, ser este o caminho para uma compreensão própria da existência, já que o impessoal se encontra impossibilitado de dar conta do fenômeno. $\mathrm{O}$ ser humano não é ou está no fim, "lá" na morte. Mas ele é para-o-fim. Numa antecedência, que deve ser existencialmente compreendida, o ser humano é e está para o seu fim continuamente. Viver e morrer são faces de um mesmo compertencimento.

Esta estrutura, a de "ser-para", que será apenas brevemente destacada, procura trazer para o pensamento a provocação essencial de que o ser humano não é simplesmente um ser mortal como outro ser vivo, mas que ele, a cada momento, é um ser-para-o-fim. Ser para o fim, a cada momento: trata-se de uma experiência "singular" num sentido diferente das demais experiências possíveis de nossa vida. Apenas o homem a experimenta. Apenas a presença que eu sou pode vivenciá-la. Sendo, sou para... o fim! De que teleologia se trata?

Não se está, meramente, fazendo a constatação de que todos somos mortais. Mas que o ser humano, a cada vez, em cada modo seu de ser, é, sendo para o seu fim. Como isso pode ser compreensível? O termo "fim" é polissêmico. Remete ora à realização de uma etapa, ora a um objetivo atingido, ora à cessação de algum ciclo de vida ou de atividade, ora a um sentido ou princípio que orienta toda e qualquer atividade desde seu "começo" até seu "fim". "O fim da vida" ou o "sentido da vida" chegam a ser idênticos. Desta forma, princípio e fim encontram-se e participam do mesmo acontecimento. Uma vida sem fim é uma vida sem norte, sem direção, projeto, sem pulso e impulso. Sendo, o homem é para o fim, sendo, simultaneamente, para o começo. Determinar a vida como sendo algo entre nascimento e morte, e nascimento e morte como sendo pontos extremos de uma vida, obedece novamente a uma determinação simplesmente evidente dos fenômenos. Para que este paradoxo - fim é começo, morte é vida, etc. - obtenha sentido, remetemos existencialmente à "mão" humana, ao conjunto de atividades em que sempre já estamos envolvidos, tanto em nossa vida "prática” quanto "teórica”. Assim, no ser-para-o-fim chama-se a atenção para o processo de criação que pertence a todas as realizações humanas.

Toda atividade tende para um aparecimento, um vir a ser, um fim. Toda atividade já está sempre pré-orientada para um fim, uma realização, do contrário ela seria impossível. Mas, ao mesmo tempo, salienta-se a possibili- 
dade do desaparecimento, de um não-ser-mais. Quando um projeto é levado a cabo, em algum momento, ele atinge seu fim, seu acabamento. Em geral, nosso pensamento racional determina o ponto de acabamento de determinada atividade: a casa está pronta, ocorreu a última pincelada de um quadro, etc. Mas, será que se esgotou, de fato, todo o projeto que está sendo levado a cabo? Será que toda a atividade cessou neste fim? Ou será que a mão humana permanece "pensando" e "agindo", isto é, continua sempre fazendo, num ritmo e num nível que nossa comum razão a custo acompanha? Ora, quando uma casa termina, terminou apenas parcialmente uma atividade de vida. Outras reivindicarão continuamente o esforço humano. Igualmente quando um artista terminou seu quadro, a arte o convocará para outros, por exemplo, e em cada projeto realizado, repercutirá o conjunto dos projetos um dia "finalizados". Esta compreensão assemelha-se a uma rede de pesca, onde um nó leva a outro e se mantém ligado a outro, perfazendo infinitas remissões dotadas de infinitos significados. Todas as atividades humanas estão atravessadas por este comportamento. Viver é agir. O trabalho continua, pois o ser humano não pode deixar de "fazer". O fim, a finalidade, possui algo de elevado, em sendo aquele "instante" que, mesmo sem se ter clareza, orienta a cada vez todos os passos e procedimentos em determinado projeto existencial. Mas este instante não pode ser esgotado na determinação de um "momento fatual”. Sempre há o fim. Ele, o fim, já era "no" começo. Tudo o que é, o que nasce, encontra seu sentido - seu momento de maior concentração e expressão - no fim e a partir do fim. A unidade dinâmica de começo e fim deve orientar-nos. Por ela acedemos ao modo como devemos compreender nosso ser-para-a-morte e visualizaremos o contexto em que esta articulação se aplica à vida humana. Mas como, nesta infinita rede de possibilidades, podemos alcançar uma compreensão existencial do conjunto, da totalidade?

$\mathrm{Na}$ experiência do homem ser para a sua morte, para o seu fim, apresenta-se, então, uma experiência de "totalidade" que se distingue de uma noção de "soma" ou "acréscimo". Em cada atividade, a cada momento, de acordo com o ser-no-mundo que nós somos, nós somos sempre de forma integral, e não pela metade. Estamos envolvidos inteiramente sendo junto com determinada atividade ou em determinada convivência. Mesmo quando nós nos imaginamos numa atividade dissimulada, onde não revelamos todos os verdadeiros interesses, mesmo assim nós ali estamos de forma integral, numa experiência "dissimulada" de vida. Sendo junto com, somos desta ou daquela maneira. Desta forma, a compreensão ontológica de totalidade, de 
ser todo, inteiro, e não pela metade, distingue-se de uma compreensão corriqueira que elege alguma espécie de padrão de completude de acordo com algum modelo haurido da moralidade, da produtividade, da funcionalidade para atingir determinados fins, etc. Expliquemos um pouco mais. Os indivíduos são convocados a fazerem parte, a serem num e para um todo chamado "empresa”, "time”, "equipe”, "nação", "grupo social, político, artístico”, etc. A nosso ver, a totalidade não pode ser fixada como algum ideal universal a posteriori, alcançado quando cada um se "encaixa" ou exerce, simplesmente, a sua "função". Esta seria artificial e levantaria muitos problemas. Artificial porque seria alcançada mediante algum artifício ou técnica humana em sentido amplo. E isto geraria ainda o problema de se determinar como e quando esta ou aquela totalidade "desejada" seria alcançada. Somaríamos as partes e quando todas estivessem em seu devido lugar, atingiríamos a totalidade. Mas, de quantas partes é composto o todo? Se não sabemos, como garantir que não falte alguma parte? E se faltar, ou puder faltar, esta compreensão de totalidade não se tornará inalcançável?

Como compreender, então, existencialmente a totalidade? Como esta totalidade pode ser, a cada vez e continuamente, acessível e visível? Pertence, existencialmente, à compreensão de totalidade visada, a falta, a incompletude, a carência. A possibilidade de não ser. Todo e não-todo (parte) perfazem uma mesma e única dinâmica. Mas, em que sentido? Pois compreendemos perfeitamente que numa totalidade artificialmente construída - um indivíduo que entra para a equipe de uma empresa - totalidade pré-existente, sempre falta algo, o que não compromete sua estrutura. Em determina trabalho sempre ocorrerão acréscimos, mudanças, reorientações dos processos e dos objetivos a fim de que o plano acordado em equipe seja atingido. Mas em que sentido o que "falta" está sendo aqui compreendido? Ainda como aquilo que pode ser somado, como acréscimo ou mudança dentro de uma estrutura previamente planejada. Pode-se dizer que, neste caso, não há uma totalidade, mas ela está sendo construída de modo "inadequado", pois sempre poderá faltar algo. O problema está em nosso modo de compreensão e não no exemplo citado. Como seria então esta totalidade existencial, caracterizada por uma falta, uma carência e que não pode ser resolvida acrescentando-se aqui e ali o que falta? É aqui que o ser-para-a-morte, existencialmente compreendido, pode nos auxiliar. O que falta não é acrescentado ao que é, deixando de ser falta, mas pertence continuamente ao que é, compondo seu conteúdo existencial: ser e não-ser, vida e morte. $\mathrm{O}$ não-ser em todo ser, a morte em toda 
vida; o não-ser no ser todo, a morte na vida toda. Em outras palavras, está presente, a cada vez, em cada atividade, a possibilidade dela acabar, ruir. Isto a torna incompleta? Muito pelo contrário. Esta falta presente faz com que a dinâmica que sustenta a atividade se mantenha. Neste sentido, a totalidade, existencialmente compreendida, distingue-se de uma totalidade universal ou geral, sendo, a cada vez, uma totalidade finita. Ela torna-se visível não na construção de um conjunto genérico de entes, mas na percepção da ação ou do modo de ação presente em cada atividade. Isto não é nada de artificial ou de fictício. Esta possibilidade, por exemplo, exige que seus membros, em determinado contexto, mantenham-se atentos, aguçados, na realização de determinada atividade. Ou seja, o perigo de perder-se, de dar tudo errado, do fracasso, pertence a toda ação enquanto ela é. São exatamente as possibilidades de fracasso, de perigo, de incompletude, que movem os seres humanos a poderem recusar formas impessoais de totalidade e, com isso, a experimentarem a sua existência como uma tarefa intransferível. Esta análise dos diz que sendo, a vida é, e que ao mesmo tempo, ela pode não ser. Por meio da experiência da morte somos acordados para esta totalidade de forma penetrante. A cada momento é a vida inteira que pode sucumbir e que pode ser outra, fato que continuamente escapa a nossos projetos conscientes. Esta possibilidade é imanente ao fenômeno em questão. Ser é ser também e continuamente para o fim aqui e agora.

Em sendo para o fim, aqui e agora, aparece a questão pela totalidade que pertence ao ser humano. Trata-se de uma busca e não de um mero interrogatório sobre a totalidade. $\mathrm{Na}$ experiência de ser-para-a-morte mostra-se, formalmente, o extremo não-ser da vida, a morte, como sendo enquanto o ser humano é, vive. Desta forma, a morte é incorporada à vida. Mas pode-se e deve-se sempre perguntar: Quando experimentamos esta totalidade da existência? Quando o ser-todo atinge sua máxima expressão? Dissemos ser coisa diferente de somar, acrescentar, etc. Dissemos pertencer a cada atividade humana, "verdadeira" ou "fingida". Dissemos que a falta, o não-ser, estão presentes em todo ser. Acrescentemos mais um aspecto. Este adverte continuamente a nós, filósofos-espectadores, convocando-nos “à intuição" da singularidade que pertence a toda atividade, à vida, e ao silêncio provocante que a reveste como uma aura.

Quando determinada atividade, ou ação, está sendo, não há, de certa forma "interrupção", na forma de perguntas, planejamentos, etc. Há trabalho, trabalho ininterrupto, e menos "teoria". Do próprio trabalho, isto é, da 
atividade, vem toda lei, toda regra, toda possível e necessária mudança para o desenvolvimento da atividade. A atividade do artista continua sendo um protótipo. Assim, agindo, obedecendo ao toque da coisa, da atividade, sintonizados com o que está em questão: experimentamos a totalidade, não carecemos de perguntas exteriores, somos sem "por quê" e sem "para quê". Apenas sendo. Nesta totalidade somos-para, estamos em nosso ser-para a cada vez, sendo. Mas, de que forma isto diz respeito à morte? Pois acrescentar "teoricamente" a morte à vida num belo arrazoado, apenas responde "intelectualmente” à questão da totalidade. E, existencialmente? Poderíamos fazer uma breve indicação, sem nos alongarmos, e repetindo o que já acenamos: quando a morte deixa de ser problema, de ser questão, de ser uma aporia a ser solucionada. Aqui, não se trata de dissimulação, mas de experiência impartilhável. Por isso seu caráter silencioso. Isto é, quando ela, em seu modo de ser, é. Quando nós, sendo-para-a-nossa-morte, a deixamos ser, sem desejarmos encaixá-la em nossos esquemas racionais ou irracionais. Ocorre uma estranha transformação ou "transubstanciação" da coisa "morte". É com uma intuição de artista que Leão Tolstoi nos diz, já no final de sua novela $A$ morte de Ivan Ilitch: “'E a morte... Onde está?' Procurou o temor cotidiano da morte e não o encontrou. 'Onde está? Que morte?' Não havia temor, porque não havia morte". E mais adiante: "Acabou a Morte', pensou. 'A Morte já não existe!'. Aspirou profundamente, interrompeu a respiração, inteiriçou-se e morreu" 12 .

Cada atividade singular e a possibilidade de não ser mais, de morrer, estão, a cada vez, em jogo. Todas as possibilidades vitais submetem-se e se deixam ver como possibilidades a partir da possibilidade extrema da morte. É como se a morte aparecesse como um estranho farol que, em seu poder aniquilador, nos conduzisse a avaliar ou hierarquizar todas as circunstâncias reais de vida. É desta forma que priorizamos certos afazeres. Assim, este serpara, esta remissão a uma experiência privilegiada, é o que é visado na problemática existencial desdobrada em Ser e tempo. Citemos Heidegger, onde uma compreensão própria da morte, através de alguns de seus momentos essenciais, acena também para uma compreensão da totalidade humana.

...A morte desvela-se como a possibilidade mais própria, irremissível e insuperável. Como tal, ela é um impendente privi-

12 TOLSTOI, Leão. A morte de Ivan Ilitch. Rio de Janeiro : Lacerda editores, 1997, p. 91. 
legiado. Essa possibilidade existencial funda-se em que a presença está, essencialmente, aberta para si mesma e isso no modo de anteceder-a-si-mesma. Esse momento estrutural da cura [Sorge] possui sua concreção mais originária no ser-paraa-morte. O ser-para-o-fim torna-se, fenomenalmente, mais claro como ser-para essa possibilidade privilegiada da presença ${ }^{13}$.

A presença está aberta, isto é, disposta ou lançada continuamente para a possibilidade da morte. Qual o teor desta abertura? Como possibilidade a morte é pré-vista. Trata-se, desta forma, de uma experiência essencialmente e somente antecipadora. Uma experiência que aponta, como caminho de compreensão humana, o fenômeno da antecipação. Esta antecipação encontra expressão privilegiada na experiência de ser-para-a-morte: é a partir desta experiência que a antecipação se dá à compreensão de forma explícita. E este mesmo ser-para-o-fim, aponta para a totalidade da presença, a cura: “já anteceder-a-si-mesma-em (um mundo) como ser-junto-aos entes (intramundanos) que vêm ao encontro"14. Morte e totalidade possuem uma afinidade existencial. Por isso necessitamos agora explorar esta noção de possibilidade e de antecipação. Por meio delas ampliaremos nossa compreensão do fenômeno da morte e da totalidade que lhe pertence.

\section{A possibilidade privilegiada da morte.}

"A morte é uma possibilidade privilegiada da presença"15. Desta forma ela não pode ser interpretada como algo simplesmente dado, como algo evidente e, a partir daí, isento de questionamento. Ela não se constitui como algo "fora" do ser do homem. Se assim o fosse e se ela fosse simplesmente "acrescentada" ao seu ser, este deixaria de existir. Mas a morte perfaz o ser do homem, pertencendo-lhe de modo ímpar enquanto ele é, isto é, enquanto ele vive. $\mathrm{O}$ ser humano finda e não fina como qualquer ser vivo simplesmente existente. Conseqüentemente podemos dizer serem formas inadequadas de interpretação do fenômeno da morte aquelas que partem de uma noção que toma como base compreensiva (comparativamente) a morte dos seres vivos em geral ou de um entendimento da morte (e de fim, término) que não in-

\footnotetext{
${ }^{13}$ ST $§ 50$, p. 326.

${ }^{14}$ Cf. ST §41, p. 259-260.

${ }_{15}$ ST $\S 49$, p. 323.
} 
vestiga a proveniência destes fenômenos. Estas interpretações passam por cima da singularidade da experiência da morte como minha morte. Tais deficiências interpretativas, como já o dissemos, demonstraram a necessidade de se construir um conceito existencial da morte. Este conceito não deve ser entendido como uma definição nova, ignorada pela filosofia, mas como uma compreensão que leva em conta o fato humano de ser já sempre engajado num mundo de relações e sempre à mercê das influências deste mundo. Somente uma abordagem deste tipo poderá interpretar adequadamente a morte inserida na vida humana. Nem o ser humano, nem a morte que lhe diz respeito, são seres simplesmente dados.

Segundo Ser e tempo, a abordagem adequada do fenômeno da morte só pode nascer a partir de uma interpretação que tome como fio condutor a constituição fundamental da presença. Do contrário deslizaremos para uma compreensão simplesmente dada de homem, de existência, de morte. A constituição fundamental do ente privilegiado (existência, facticidade e decadência) auxilia-nos a entender a morte como uma possibilidade da existência. É existindo, isto é, já estando desde sempre jogados ou inseridos num relacionamento possível com as coisas e com os outros (ex = fora), e já sempre contaminados por estes relacionamentos (decaídos), que nós nos encontramos frente ao fato de nossa morte. Nunca um fato puro, que seja isento de engajamento. Mas contaminado, isto é, influenciado pelos diversos contextos de convivência e de lida. A existência remete para estes contextos. Quando, a partir da experiência religiosa, ou científica, ou pessoal, etc., explicitamos o fenômeno da morte, já o fazemos sob a influência de um conjunto de remissões. Nossas mais variadas reflexões sobre a morte já pressupõem este dado elementar. E, deve-se também dizer, a morte não salta à nossa compreensão como uma "possibilidade qualquer", apesar desta interpretação não poder ser excluída de todo. Existencialmente a morte é uma possibilidade privilegiada. Vejamos, brevemente, a quê acenam as compreensões de "possibilidade" e de "privilégio".

\section{a) Possibilidade.}

A noção de possibilidade remete sempre para o possível, para o que ainda não se efetivou de fato, para o que, de certa forma, pertence ao ente que está em questão, mas que, em geral não o percebemos. Podemos acrescentar, também, que a possibilidade acena sempre para uma certa experiência de 
liberdade ou de abertura, querendo com isso indicar uma infinidade de possibilidades latentes. Umas podem, em algum momento, efetivar-se, como um fruto tornar-se maduro, e o dia converter-se em noite. Outras, talvez, permanecerão eternamente no âmbito da possibilidade, como por exemplo, a possibilidade de um indivíduo cometer determinado crime. Provavelmente nunca o fará, mas pode fazê-lo. A possibilidade partilha de tal maneira da realidade do ente que quando se torna algo real, em algum tipo de vivência, não chega a causar surpresa. A possibilidade pode revestir-se, então, de uma certa evidência, como o fruto tornar-se maduro, e o jovem adulto. Todos esperam por isso. E esta evidência, como é de se esperar, pode desviar o pensamento do que há de essencial. Percebemos a mesma situação, também, no uso das coisas. Uma caneta, numa briga de rua, pode, rapidamente, converter-se numa arma de defesa ou de ataque.

Mas com a morte não se passa exatamente a mesma coisa. É evidente que a possibilidade simplesmente dada da morte pertence a tudo o que um dia nasceu. Tanto num sentido "figurado", quanto num sentido "literal". Pensemos no "fim" de uma cidade, de um ser vivo, de uma obra de arte, de uma floresta, de um ser humano, etc. Mas, então, a morte estará lá, e eu aqui, não podendo fazer experiência da mesma, nem guardar memória desta experiência. No entanto, sabemos da morte. Nós já sempre sabemos da nossa morte e, por isso, sabemos também, de certa forma, da morte de tudo o que há. E o sabemos sempre antecipadamente. A possibilidade da morte, então, não é nada que, em algum momento, poderia tornar-se "real" e, daí, eliminar o caráter de possibilidade, de surpresa, de estranhamento, de abertura ou de poder-ser que continuamente lhe pertence. Antes o contrário! A morte é sempre possível a cada momento, não meramente no sentido de que ela pode a qualquer momento, como num acidente, tornar-se real. Ela é possível em sua "irrealidade". Nós não fazemos a experiência da realidade da morte simplesmente porque não podemos. Quando ela por fim vem, eu já não estarei vivo. A nossa experiência da morte e, com ela, a experiência de todas as paixões que ela pode despertar, permanece no âmbito da possibilidade. A compreensão existencial da morte se mantém dentro do espaço e do tempo da possibilidade, sem nenhuma concessão a qualquer compreensão simplesmente dada de realidade.

Esclareçamos esta dupla compreensão em relação à morte, a de possibilidade como o que pode tornar-se real e a de possibilidade como o que nunca pode se tornar real ou realizável. Na segunda acepção encontraremos a 
experiência existencial da morte. Citamos um texto de Heidegger para exemplificar esta reflexão de forma mais detalhada.

"Trata-se apenas de experimentar as coisas, de qualquer vizinhança, tais quais são, sem nos deixarmos seduzir por teorias apressadas. Esse pedaço de giz aqui é uma coisa extensa, relativamente consistente, de determinada forma e cor branca, e em tudo isso e com tudo isso é ainda uma coisa para escrever. Tão certo, como lhe corresponde estar aqui, do mesmo modo lhe pertence poder não estar aqui ou não ter o tamanho que tem. Poder ser conduzido pelo quadro negro e gasto não é algo, que the acrescentamos apenas com o pensamento. Ele mesmo, como o ente que é, está nessa possibilidade, do contrário não seria um giz, qual instrumento para escrever na pedra. Correspondentemente, todo ente traz consigo, de modo diferente em cada caso, uma tal possibilidade. Essa possibilidade pertence ao giz. É ele que tem consigo mesmo determinada possibilidade para determinado uso. Sem dúvida, na procura dessas possibilidades estamos habituados e inclinados a dizer, que não as vemos nem tocamos. É um preconceito. Afastá-lo pertence ao desenvolvimento da questão. Por enquanto, porém, ela tem apenas de descobrir o ente em sua oscilação entre o ser e o não-ser. Resistindo à suprema possibilidade do não-ser, o ente in-siste no ser, embora não tenha nunca ultrapassado e superado a possibilidade do não-ser" 16 .

$\mathrm{O}$ contexto imediato do texto citado visa à compreensão do ser. Falase do ente, do que é ou existe. E, junto com isso, do que faz o ente ser ente, seu sentido e fundamento. Em seu caráter de possibilidade (de poder-ser, de abertura ou liberdade), todo ente "oscila" entre ser e não-ser, querendo expressar a situação ontológica de ser e não-ser ao mesmo tempo. Agir, lidar com as coisas, fazer, é, de certa forma, insistir no ser, assumir ou responsabilizar-se pelo ente nos contornos de determinada configuração ou uso de possibilidades. Não há o esparramado da existência, mas antes o situado, o circunscrito a cada vez. No trato com os entes nós os encontramos como coisas, por exemplo, exercendo determinadas funções em diversos campos de

${ }^{16}$ HEIDEGGER, Martin. Introdução à metafísica. Rio de Janeiro : Ed. Tempo Brasileiro, 1969, p. 58, grifos nossos. 
atividades. Neste contexto o possível torna-se real e realizável estimulando ou ampliando toda ação e compreensão do canteiro de obras. $O$ artesão desenvolve (como todo ser humano), em seu trabalho, aquele olhar que enxerga o que ainda não é, mas que pertence essencialmente à coisa. Por isso esforça-se para realizar ou efetivar a obra. Este processo pertence ao vir-a-ser da obra. Mas, curiosamente, se toda possibilidade de não-ser, isto é, de possibilidade e de estranhamento diante do ser, fosse realizável, esgotável, o não-ser deixaria de existir como não-ser, como possibilidade ou poder-ser daquilo que é. Então estaríamos diante da imobilidade absoluta da existência. Mas, uma pintura não chega ao seu fim na última pincelada? Talvez em sua pertinência ao artista-criador. Após, ela terá um novo começo, junto às coisas artísticas, que convocarão os olhares e despertarão ou provocarão sentimentos ou idéias antes obstruídos. O não-ser não foi eliminado, visto que seu caráter de inacabamento convoca todo espectador, por assim dizer, a fazer e refazer em cada contemplação ou discussão, o ser da obra de arte. A coisa está ali e, simultaneamente, ao lidarmos desta ou daquela maneira com o seu "estar ali", percebemos que algo lhe falta, ou que há mais em seu "estar ali". Desta feita, a coisa acaba sendo construída, feita e refeita. O não-ser, como o apresentamos, continua previamente presente. A extinção do não-ser no ser, de forma absoluta, retiraria das coisas a serem realizadas seu outro lado, a possibilidade de serem, a cada vez, algo outro do que são ou se mostram e, junto com isso, a possibilidade de estranhamento, admiração, não-saber que caracteriza toda experiência humana essencial. A extinção do não-ser no ser, se isto fosse possível, retiraria toda dinâmica, geração e corrupção, todo movimento ou vida das coisas. Por isso, em todo modo de existir, o ser humano afirma a existência do ente, resistindo, a cada vez, à possibilidade extrema do não-ser, "insistindo no ser". Mas isto de forma alguma o faz ultrapassar a possibilidade do não-ser. Em cada ação a vida é afirmada, mas isto não a faz ultrapassar a possibilidade da morte. No entanto, a insistência no ser se dá porque, previamente, o não-ser já sempre nos afetou.

Percebemos, então, que a possibilidade da morte, o poder-ser que pertence ao ser humano vivendo, consiste numa experiência que nunca pode tornar-se real, segundo o modo como as possibilidades das coisas podem tornar-se reais ou realizáveis. A morte permanece como o "não" de todo ser, como o completo e absoluto não-ser que resiste a toda insistência pelo ser. Não devemos ver nisto apenas um aspecto "negativo" ou "destrutivo" da existência. Pois a possibilidade do fim habita a mesma casa que a possibilida- 
de da vida. Precisamos perceber ali uma constituição fundamental da vida mesma que, em sua possibilidade de não-ser, peleja contra toda fixidez ou cristalização da vida na sedução ou conforto das realizações de ser.

\title{
b) Privilégio.
}

A morte é uma possibilidade privilegiada. Acentuemos, agora, este aspecto privilegiado. Retornemos a Ser e tempo. Ser-para-a-morte é ser para uma possibilidade privilegiada. Por quê?

\begin{abstract}
"Quanto mais se compreender e desvelar essa possibilidade, tanto mais puramente a compreensão penetra na possibilidade como a possibilidade da impossibilidade da existência. (...) É a possibilidade da impossibilidade de toda relação com..., de todo existir. No antecipar, a possibilidade 'será sempre maior', ou seja, desvela-se como aquela que desconhece toda medida, todo mais ou menos, significando a possibilidade da impossibilidade, sem medida, da existência. Em sua essência, essa possibilidade não oferece nenhum apoio para alguma expectativa e para se 'configurar' um real possível e, assim, esquecer a possibilidade. Enquanto antecipação da possibilidade, o ser-para-a-morte é que possibilita essa possibilidade e que a libera como tal”17.
\end{abstract}

A possibilidade da morte, que se revela para o ser humano em sendopara-a-sua-morte, apresenta-a como aquela possibilidade que, em sendo, põe em perigo toda a existência. Por meio desta possibilidade torna-se patente evidente - que a existência pode não ser mais, isto é, que eu, mundo, todas as remissões para com as coisas, podem não ser mais, que toda pretensa segurança e estabilidade junto aos outros e às coisas, podem não ser mais. $\mathrm{O}$ fato terrível de que tudo é passageiro e de que toda estabilidade - de coisas e de "pensamentos" - pode seguir para sua ruína, atinge o ser humano. Eu posso não-ser e, com isso, nada mais. Desta forma, apenas chamamos a atenção para a possibilidade da experiência da morte conduzir todo ente para dentro

${ }_{17} \mathrm{ST} \S 53$, p. 339. 
do "nada", o que angustia e desafia todo pensamento ${ }^{18}$. O fio de Ariadne, que me mantinha seguro na vida, mostrou-se em sua fragilidade. À medida que esta possibilidade, a possibilidade da nossa morte, atingir nossa compreensão e ali fincar raízes, ela pode se revelar em toda a sua força: todo cálculo, medida, segurança, certeza, pressuposição, projeto, etc., da existência conhece seu extremo limite, ou melhor, vê-se absorvido em seu fim. Com a possibilidade antecipada da morte não se pode fazer nada, e também, em nosso caso, não se pode esquecê-la como possibilidade. A compreensão da morte, aqui evocada, deve permanecer sob as luzes da possibilidade, isto é, esta compreensão deve ser suportada e construída como possibilidade ${ }^{19}$.

Mas, devemos salientar o ponto principal de forma mais direta. A morte somente pode ser experimentada pelo ser humano de forma antecipada. Neste espaço e tempo da antecipação, assim revelados, toda outra possibilidade junto às coisas e aos outros perde seu caráter absoluto. Neste sentido, a possibilidade antecipada da morte detém o privilégio de ser aquela possibilidade que permite a existência de todas as outras possibilidades, enquanto ela não se concretizar. Sua realização seria o fim de todo ente. No entanto, há um aspecto ainda mais importante para uma compreensão ontológicoexistencial. Já que a morte não pode ser realizada, e apenas pode ser experimentada antecipadamente como possibilidade extrema e incontornável da existência, como o não-ser de todo ser, esta mesma experiência libera a experiência da possibilidade como o lugar privilegiado da existência. É em sendopara-a-sua-morte que a morte exige que o ser humano saiba dela, a apreenda, de modo antecipado. Sua possibilidade apenas assim pode se dar. E, simultaneamente, este espaço da possibilidade redimensiona todo o olhar para a realidade. Antes de toda realização, antes de todo ser junto aos outros e com as coisas, o ser humano é ou está atado ao modo de ser de possibilidade. É ou está atado a um modo de "ser-para", um poder-ser, uma liberdade. E isto sempre, desde sempre, originalmente, antecipadamente. A morado do ser humano revela-se como a antecipação da possibilidade onde a possibilidade da morte nos afeta como a possibilidade. Nesta afetação, o que nos contamina mesmo não é "meramente" a morte, mas sua possibilidade. Antes de toda

\footnotetext{
${ }^{18}$ Cf. HEIDEGGER, M. Que é metafísica. In: Conferências e escritos filosóficos. Coleção Os Pensadores, São Paulo: Nova Cultural, 1989, p. 36.

${ }_{19}$ Cf. ST § 53, p. 338.
} 
realidade, ou, mais elevada do que a realidade está a possibilidade ${ }^{20}$. Foi e é a experiência da morte que joga e libera o ser humano para esta mais radical experiência de si mesmo. Esta experiência sugere apenas que antes de todo ser, o ser humano já estava no não-ser, que antes de toda determinação, o ser humano já vivia uma indeterminação, que antes de toda situação, os ser humano já sempre estava remetido para uma localização. Sugere o aspecto trágico da vida humana não ser nunca algo acabado e pronto, nem o "sujeito" que nós somos algo simplesmente de primeiro, mas tão simplesmente um a-se-fazer, uma dinâmica de auto-constituição, uma possibilidade de ser.

A morte se revela como existencial a partir da experiência do ser humano como ser-para-a-morte, ou, se melhor o desejarmos, o fim próprio do ser humano como um ser-para-o-fim. Percebemos que sempre sabemos antecipadamente de nossa morte, por mais tênue que seja este saber. Simultaneamente, neste saber antecipatório acerca da morte e de nós mesmos como seres mortais, salta aos olhos a existência de um "hiato" extremamente angustiante e insuperável, no qual existimos a partir da possibilidade e para a possibilidade, não podendo existencialmente fundar tais experiências em alguma compreensão simplesmente dada, real. Neste "hiato" podemos encontrar as experiências de abertura e de poder-ser, de antecipação e de possibilidade, aludidas acima.

Se a morte se mostra ou se revela no ser humano não como qualquer coisa simplesmente dada, mas como ser-para-o-fim, este "para-o", esta conexão ou imbricação essencial, deve ser continuamente demonstrada. Ser-para o fim, ser-para a morte, ser-para a antecipação da possibilidade da morte, serpara o seu poder-ser, pura e simplesmente.

De certa forma, "a presença já está lançada nessa possibilidade"21. Ela já sempre se encontra, e não pode não se encontrar, num relacionamento com a possibilidade da morte de modo próprio, irremissível e insuperável. O que ocorre é que, em geral, o ser humano "não possui nenhum saber explícito ou mesmo teórico" 22 desta experiência. "É na disposição da angústia que o estar-lançado na morte se desvela para a presença de modo mais originário e penetrante"23. A angústia desperta o ser humano para o fato de seu ser.

\footnotetext{
20 Cf. ST §7, p. 78

${ }^{21} \mathrm{ST} \S 50$, p. 326.

22 ST § 50, p. 326.

${ }_{23}$ ST § 50, p. 326.
} 
Ontologicamente, este páthos conduz toda investigação. Seu caráter de fundo e de primazia na determinação do ser do homem não deve ser subestimado pelo fato de, corriqueiramente, as pessoas não se mostrarem angustiadas. Esta experiência desestrutura de tal modo o ser humano que, em geral, o nosso comportamento mais comum é o de desviar-se e fugir de sua força nas ocupações e preocupações mais diversas e sob diferentes camuflagens interpretativas, confundindo-se a angústia com o temor, com o medo de algo. Angustiado, o ser humano encontra sua existência como estando ou sendo perigosa, isto é, esta perde todo seu caráter de evidência. $\mathrm{E}$, com isso, o próprio ser, a própria vida. "A angústia com a morte é angústia 'com' o poder-ser mais próprio, irremissível e insuperável”24. Angustiado o ser humano dá-se conta de que ele, já não sendo mais, nada mais poderá ser ou fazer, esgotando-se todas as suas possibilidades de existência. Desta forma esta disposição joga o ser humano para o fato de sua singularidade insuperável, para o ser-nomundo que ele, cada vez, é. A angústia não se angustia com nenhum ente intramundano, diante do qual possa tomar uma atitude, como diante de algo que ameace o ser humano. A partir da angústia nenhum ente intramundano ameaça o ser. É com o próprio ser-no-mundo que a angústia se angustia, com seu modo de ser assim percebido. $O$ pensamento descobre a ameaça à sua existência em seu próprio modo de ser. Dizer que "a angústia se angustia" expressa a noção de que não é o ser humano que produz algum páthos para si, mas que, ao contrário, são as próprias disposições que o possuem, que o tomam, que o dominam. A existência de um "sujeito" será sempre a posteriori. A angústia com a morte já sempre tomou o ser humano. Por isso mesmo, e pelo seu "perigo" evidente, permanece em geral oculta nos mais diversos modos de fuga e de desvio da morte. "O ser-para-a-morte é, essencialmente, angústia"25.

Nosso texto preocupou-se com uma conquista existencial-filosófica da experiência da morte. Não foi nosso objetivo relatar casos de morte, nem buscar uma resposta ou sentido "metafísico" para a morte, nem concluir pela impossibilidade de uma reflexão filosófica deste tema. A partir da experiência

${ }^{24}$ ST $\S 50$, p. 326.

${ }_{25}$ ST §53, p. 343. 
da morte, existencialmente trabalhada, vêm à tona nossa existência fatual. Frisamos que a morte não deve ser interpretada como algo simplesmente dado. Neste caminho deslizaríamos infinitamente entre a vida e a morte, entre homem e mundo, etc., como se, de fato, houvesse uma espécie de exclusão ou oposição infinitas. Percebemos que, desta forma, seria impossível ao ser humano fazer sua própria experiência da morte. Mas, quando enveredamos por uma interpretação existencial da morte, interpretação que leva em conta a morte como um fenômeno que "é" enquanto o ser humano "é", vive, descobrimos uma experiência singular, própria do ser humano. Uma experiência que é, por sua vez, reveladora. Sempre sabemos de nossa morte, mesmo que de forma confusa. Isto nos diz que sempre somos para nossa morte, sabemos dela, antecipadamente. Antes de toda morte como "acontecimento efetivo”, nós já sempre somos para ela, ela tem um sentido, um significado, inclusive aquele dela ser algo como o "fim de um organismo vivo". A morte não é um "nada". Somos para a nossa morte antecipadamente. Como ela se dá a nós nesta antecipação? Com esta reflexão, buscamos uma estrutura ontológica fundada na experiência existencial. Ela se dá como possibilidade antecipada, unicamente e sempre. Ela somente pode ser pensada como "minha" morte neste "espaço" da possibilidade antecipada, na impossibilidade de qualquer forma de realização. Eu sou, estou vivo, e comigo todas as possibilidades existenciais, enquanto a possibilidade da morte não se realizar. $\mathrm{O}$ caráter aparentemente sólido, rígido, das ações e coisas humanas, vacila diante da primazia da experiência da morte. Mas esta experiência, ontologicamente, possui algo de último e primeiro. Nela, tudo encontra sua ruína. Mas também, a partir dela, tudo encontra seu nascimento, já que a morte revela a estrutura primordial do ser humano como a de ser, antecipadamente, possibilidade ou poder-ser. 


\section{Referências bibliográficas}

DASTUR, F. A morte. Ensaio sobre a finitude. Coleção Enfoques. Rio de Janeiro: DIFEL, 2002.

HARADA, H. Coisas, velhas e novas. À margem da espiritualidade franciscana. Bragança Paulista : IFAN, Ed. Universitária São Francisco, 2006.

HEIDEGGER, M. Ser e tempo. Trad. Revisada de Márcia de Sá Cavalcante Schuback. Petrópolis : ed. Vozes; Bragança Paulista : Ed. Universitária São Francisco, 2006. . Introdução à metafísica. Rio de Janeiro : Ed. Tempo Brasileiro, 1969. Que é metafísica. In: Conferências e escritos filosóficos. Coleção Os Pensadores, São Paulo: Nova Cultural, 1989.

SILESIUS, Â. O peregrino querubínico. São Paulo : Paulus, 1996, n. 37.

TOLSTOI, L. A morte de Ivan Ilitch. Rio de Janeiro : Lacerda editores, 1997.

E-mail: eciopisetta@yahoo.com.br

Recebido: 01/2008

Aprovado: 12/2008 